\title{
O Discurso da Análise: Ensaio Epistemológico sobre as Doutrinas do
} Discurso / Analytical Speech: Epistemological Essay in Discourse theory

\author{
Rodrigo Marcelino*
}

Recebido em 31 mar. 2019. Aprovado em 10 set. 2019.

Como citar este artigo:

MARCELINO, Rodrigo. O Discurso da Análise: Ensaio Epistemológico sobre as Doutrinas do Discurso. Revista Letras Raras. Campina Grande, v. 8, n. 3, p. Port. 247-271 / Eng. 245-268, set. 2019. ISSN 2317-2347. DOI: http://dx.doi.org/10.35572/rlr.v8i3.1355.

\begin{abstract}
RESUMO
O presente texto isola uma técnica de interpretação utilizada na cultura francesa, anglo-saxã e brasileira de teoria do discurso. O problema é motivado por uma pesquisa de tese que investiga a história mais geral da relação entre o saber da linguagem e a prática de interpretar em nossa cultura. $\mathrm{O}$ discurso da análise ou fala analítica é uma técnica que consiste na articulação dos enunciados do saber da linguagem com os enunciados do saber da história e com os enunciados do saber do sujeito para efetivar sua interpretação. Portanto, as diferenças do discurso da análise serão pontuadas para cada um dos seus enunciados em três culturas distintas, deixando em aberto a tarefa de pesquisar sua formação entre nós. Porque o discurso da análise difere sua interpretação de acordo com a cultura considerada, sendo inadequado avaliar sua presença em l'analyse du discours, discourse analysis e nas doutrinas do discurso como uma influência que aparece em cada cultura. As doutrinas do discurso no Brasil não são uma influência estrangeira, mas possuem uma formação que pode ser buscada através do discurso da análise que se funda na relação mais abrangente do saber da linguagem com a intepretação.

PALAVRAS-CHAVE: L'analyse du discours; Discourse analysis; Doutrinas do discurso; Epistemologia;
\end{abstract} Técnica de interpretação.

\section{ABSTRACT}

This paper exposes a technique of interpretation used in the French, Anglo-Saxon and Brazilian traditions of discourse theory. This problem arises from a more general study that investigates the history of the relationships between language knowledge and interpretive practice in Brazil. Analytical speech is a technique of interpretation which articulates the statements of the knowledge of language with those of history and subject. This technique differs in its interpretation according to the culture considered, and it is inappropriate to measure its presence as a foreign influence among l'analyse du discours, discourse analysis and doctrines of discourse. Thus, this paper points out some singular statements of analytical speech in different cultures and suggests the task of researching its formation in Brazil. The doctrines of discourse in Brazil are not a foreign influence, but they have a formation which can be sought through the old relationships of the knowledge of language and interpretation as indicated in analytical speech.

KEYWORDS: L'analyse du discours; Discourse analysis; doctrines of discourse; Epistemology; Technique of interpretation.

\section{Introdução}

\footnotetext{
* Doutorando do programa de pós-graduação em Linguística Aplicada da Universidade Federal do Rio de Janeiro - UFRJ. Professor de língua estrangeira da Secretaria Municipal de Educação do Rio de Janeiro SME-RJ. Rio de Janeiro, Brasil.r.marcelino@ rioeduca.net
} 


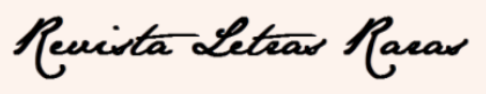

ISSN: $2317-2347$ - v. 8, n. 3 (2019)

Acode um sábio; espostejou-se a coisa: «Um, dois, três.» Sim senhor, é o que lhe digo. Verdadeira lógica intricada. É fato que a fábrica de pensamentos é como o ofício de tecelão, a cada piso que ele na apianha dá, mil fios move; voa, indo e vindo a lisa lançadeira; no urdume a trama às cegas se entretece; um golpe só fez tudo.

Goethe - Fausto

Nosso objetivo é conceituar uma técnica de interpretação que pertence às doutrinas do discurso para aquilatá-las a partir da maneira como se apresentam em nossa cultura. Destarte, iremos investigar parte da história da relação entre interpretação e linguagem que, atualmente, as doutrinas do discurso manifestam. A relação entre a prática de interpretar e o saber da linguagem se realizou de muitos modos ao longo do tempo. O que naturalmente nos leva a observar que existem várias experiências históricas do presente e do passado com as quais poderíamos dar forma a nossa investigação, como a exegese bíblica, a hermenêutica jurídica etc. Contudo, nossa preocupação principal são as doutrinas do discurso que se formaram no Brasil, nas décadas de setenta, oitenta e noventa, embora as linhas de teorias do discurso da cultura francesa e anglo-saxã sejam caminhos inevitáveis de passagem. São tão recentes que há a coexistência de gerações que viram as doutrinas do discurso passando a ser com outras gerações que quando nasceram elas já eram.

Preferimos, por uma parte, reconhecer as doutrinas do discurso no plural, evidenciando, assim, sua diversidade. A diversidade é oriunda das diferentes culturas interpretativas que as praticam, das distintas posturas diante do seu exercício, das muitas histórias sobre sua formação etc. Por serem uma experiência atuante e presente, respeitamos os conflitos e disputas que existem sob cada uma das suas perspectivas. Por outra parte, escolhemos identificá-las como doutrinas, a fim de evitar a denominação de teoria que, habitualmente, é oposta à prática, embora nem sempre isso ocorra. Caracterizar as diferentes teorias do discurso como doutrina possui a vantagem de destacar que elas não estão somente relacionadas a um esquema epistemológico organizado através de uma intricada rede de enunciados, mas que também são um conjunto de deveres estabelecidos em um código específico de conduta, como a imprensa e a pedagogia. Ambos, o esquema epistemológico e o código de costumes, são responsáveis pelo poder das técnicas de interpretação das doutrinas do discurso. 


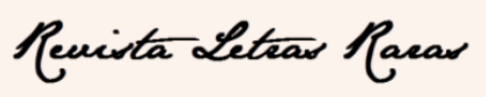

ISSN: $2317-2347$ - v. 8, n. 3 (2019)

As doutrinas do discurso são uma tradição interpretativa que recorrem ao saber da linguagem. As doutrinas que nos remetemos são aquelas que se formaram durante as décadas de setenta, oitenta e noventa do século passado entre nós. Na verdade, as doutrinas do discurso são um saber que começou em um ponto indeterminado do passado e que perdura até o presente momento, sem estarem concluídas. Isso nos dispensa de nos apegar às cronologias, que nos servem apenas como orientação na investigação da relação da prática de interpretar com o saber da linguagem tal como se materializa com as doutrinas do discurso.

No exercício da prática de interpretar, as doutrinas do discurso não se diferenciam por recorrerem ao saber da linguagem, tendo em vista que isso acontece com outras técnicas de interpretação. O que as singulariza na sua arte de interpretar é uma certa articulação entre enunciados - o saber da linguagem é articulado ao saber da história e ao saber do sujeito. As doutrinas do discurso são muito complexas e, pelo fato de serem uma experiência cultural presente, tornaram-se difíceis de serem circunscritas de modo que alguém possa esgotá-las. Nem é nossa essa pretensão. Mesmo se devêssemos considerar tal articulação entre enunciados como um produto das doutrinas do discurso, ela, contudo, não é todo o acontecimento, pois é preciso que haja algo fora desse limite, existem termos médios cujo valor não se acha determinado e os fatores conhecidos não esgotam a série, que servem senão como parte de seu acionamento. Destacar o saber da linguagem articulado com o saber da história e com saber do sujeito, dentro da experiência das doutrinas do discurso, significa tratar de uma literatura menor de uma cultura interpretativa. $O$ presente ensaio ${ }^{1}$ introduz as expressões "discurso da análise" ou "fala analítica" para mostrar a articulação do saber da linguagem com o saber da história e o saber do sujeito, que se configura como o nosso alvo de investigação principal.

O discurso da análise é uma técnica de interpretação que consiste em capturar a experiência analisada através de uma sucessão ininterrupta e limitada de três enunciados que se referenciam mutuamente. Uma sequência finita de enunciados, na qual cada enunciado depende de um anterior ou é explicado por um posterior. Assim, um primeiro enunciado presente e imediato entra em relação com um segundo que não é ele e que pode ser pensado, explicado ou afirmado por ele, decorrendo um encadeamento no qual

\footnotetext{
${ }^{1}$ Este ensaio é fruto de uma tese em curso.
} 


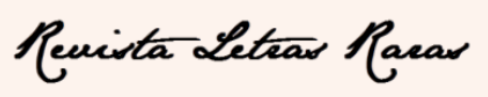

ISSN: $2317-2347$ - v. 8, n. 3 (2019)

o segundo enunciado se esclareceria por um terceiro que, por sua vez, seria dependente do primeiro da série. Por exemplo, podemos esperar que a linguagem seja explicada pela história e que a história, por sua vez, seja esclarecida pelo sujeito ${ }^{2}$. Isso aconteceria em uma amostra de jogo ideal, pois são possíveis diversas variações. Inclusive, o preenchimento da primeira posição é livre, assim como o preenchimento das demais. Seria possível começar com uma outra amostra, na qual o sujeito preenchesse a primeira posição e fosse sucedido por qualquer dos outros saberes e suas derivações, indistintamente. Poderia até mesmo acontecer de um saber ser articulado às derivações do seu próprio arco semântico, antes de se articular com um outro saber qualquer. Derivações no sentido que a história poderia se passar por arquivo, narrativa etc., a linguagem poderia ser substituída por língua, idioma etc. e o sujeito poderia ser trocado por agente, pessoa etc. Há uma completa falta de ordem e de um caminho definido entre os enunciados da cadeia do discurso da análise, o que permite a cada vez uma interpretação diferente segundo o repertório cultural e a experiência levada em consideração. O que fica do movimento e da dinâmica do discurso da análise é que um enunciado se articula em um outro enunciado mais explícito. O discurso da análise nada indica, seu enunciado se remete senão para outro enunciado.

Isso é o máximo que podemos exibir, pois o que pode ser mostrado, não pode ser dito. O discurso da análise não é suscetível de ter seus vestígios seguidos separadamente da experiência na qual é empregado e a partir da qual se realiza. Ele constitui uma articulação de enunciados cujas instâncias realizadas não esgotam suas possibilidades combinatórias. Agora também entendemos nosso sentimento; estaremos de posse de uma concepção logicamente correta uma vez que tudo esteja conforme em uma cultura.

A fala analítica é uma técnica de intepretação que aparece na cultura francesa, com l'analyse du discours ${ }^{3}$, na cultura anglo-saxã, com discourse analysis e, no Brasil, com as doutrinas do discurso. O discurso da análise possui uma história que se diferencia em cada cultura. Tomamos a iniciativa de apresentar e mostrar a técnica de interpretação que se designou por fala analítica ou discurso da análise se manifestando em diferentes culturas, para que tais amostras deem vida ao nosso objetivo de conceituar

\footnotetext{
${ }^{2}$ Lembrando que não temos comprometimento algum com as amostras. Elas são apenas uma maneira de emular, por assim dizer, o discurso da análise.

3 Ao nos remetermos à Linguística Aplicada, ou a qualquer outro território de saber, como discourse analysis, antropofagia, marxismo etc. deve-se levar em consideração, como referência, os autores realmente citados relacionados ao sintagma ao longo do texto.
} 


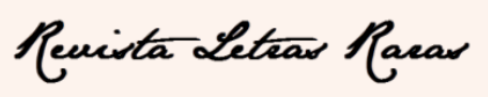

ISSN: $2317-2347$ - v. 8, n. 3 (2019)

essa prática. Para isso, o texto será dividido de acordo com as manifestações do discurso da análise em cada cultura. Na primeira seção, a cultura francesa será abordada, na segunda seção, a cultura anglo-saxã e, na última seção, a cultura brasileira. O objetivo de conceituar uma técnica de interpretação no seio das doutrinas do discurso será alcançado à medida que o discurso da análise tomar corpo segundo a descrição de cada uma dessas experiências culturais, salvaguardando as particularidades devidas, sempre que necessário.

\section{L'analyse du discours}

Na França, a fala analítica está presente na l'analyse du discours. O discurso da análise pode ser muito bem notado no colóquio Materialidades Discursivas que aconteceu na Universidade Paris X, em Nanterre, em abril de 1980. A questão interpretativa era precisamente colocada como resultado de uma heterogeneidade irredutível entre história, linguagem e inconsciente (PÊCHEUX, 1980, p.15). Alguns anos antes, a articulação entre história, linguagem e inconsciente foi chamada por Michel Pêcheux (1978) de Tríplice Entente. Era assim que designava o encontro de uma base teórica nova em torno de Marx, Saussure e Freud, passados pela leitura cultural estruturalista de Althusser e Lacan. A base desse encontro existe já em 1975, no texto que Pêcheux assina com Catherine Fuchs. O colóquio possuía como tema uma pergunta de caráter diretor: para onde vai l'analyse du discours? Questão que envolvia o discurso na articulação entre Linguística, História e Psicanálise, para a qual cada participante do encontro possuía uma maneira própria de contribuir.

Acontece que o discurso da análise não foi parte exclusiva da base interpretativa do grupo que se reunirá em torno de Pêcheux. Ele estava presente na cultura francesa como um todo. Em 1964, a revista do Partido Comunista Francês, La Nouvelle Critique, havia publicado um artigo de Louis Althusser que continha o discurso da análise. A motivação desse texto era, sobretudo, manifestar a importância teórica de retornar a Freud, mais precisamente, de "instar os membros do PCF a reconhecerem a cientificidade da Psicanálise e da importância da interpretação Lacaniana desta" (ALTHUSSER, 1969, p.103). Havia o reconhecimento de que a teorização de Lacan teria sido impossível sem o surgimento de uma nova ciência, "as aquisições de Saussure 


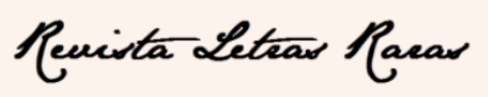

ISSN: $2317-2347$ - v. 8, n. 3 (2019)

e da Linguística". Se, na história da razão ocidental, as ciências nascem sob um grande cuidado, são planejadas e com elas são tomadas as devidas precauções, "duas ou três crianças nasceram sem serem esperadas: Marx, Nietzsche, Freud”. Althusser falava deles "porque foram nascimento de ciência e crítica" no século XIX (ALTHUSSER, 1964, p.32, 63).

No mesmo ano, alguns meses depois, em uma mesa redonda do Colóquio de Royaumont, Michel Foucault (1964), que é parte da formação da l'analyse du discours (MARCELINO, 2013), sugeriria o viés de que Marx, Nietzsche e Freud "fundaram novamente a possibilidade de uma nova hermenêutica" (FOUCAULT, 1964 p.42). Na avaliação de As Palavras e as Coisas (1966) o aparecimento dessas técnicas de interpretação se deve ao fato que no século XIX a linguagem retornou à densidade enigmática que tinha no Renascimento. "O primeiro livro do Capital é uma exegese do "valor"; Nietzsche inteiro, uma exegese de alguns vocábulos gregos; Freud, a exegese de todas essas frases mudas que sustentam e escavam os discursos aparentes, nossos fantasmas, nossos sonhos, nosso corpo". A técnica de interpretação que cada um dos três repete manifesta o reaparecimento da linguagem como objeto do saber, livre da representação que era o núcleo da episteme da idade clássica (FOUCAULT, 1966, p.412). Mas em contraposição à interpretação do século XVI, que se definia como infinita, julgada pelos limites da semelhança, dispersa em um espaço homogêneo sempre igual em todas as direções, a nova hermenêutica do século XIX mergulharia na profundidade do exterior da linguagem, em um trabalho interminável medido pela finitude natural do homem.

Se "Nietzsche, Marx e Freud" foram "grandes investigadores que abriram novos caminhos", coube a Jean Hypollite (1966), no seu último trabalho em vida, levantar a questão fundamental de saber se "continuaram o pensamento filosófico e metafísico, ou se lhe fizeram a crítica. Que pode significar um pensamento que não pertence nem à ciência positiva nem à antologia clássica? Qual é o lugar desse pensamento e de sua linguagem?” (1966, p.170).

A reposta de Foucault afirma que esses rapazes marcaram alguns pontos cruciais para a intepretação que, em seu estatuto moderno, concede primazia aos signos. Aconteceu que a interpretação se tornou uma tarefa infinita, o próprio intérprete desapareceu e nada haveria para interpretar, o signo se torna malévolo, é uma máscara. 


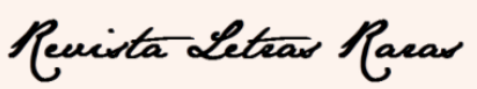

ISSN: 2317-2347 - v. 8, n. 3 (2019)

Toda interpretação deve se curvar sobre si pela indagação do quem interpreta e pela obrigação circular de passar incessantemente por onde já havia passado (FOUCAULT, 1964, p.45-49). Para Paul Ricoeur (1965), ao contrário, “Todos os três - Nietzsche, Freud e Marx - liberam nosso horizonte para um falar autêntico, um novo regime de verdade, não somente por meio da "destruição" senão pela invenção de uma arte de interpretar"4 (1965, p.149).

Fora dos nomes próprios, Diferença e Repetição (1968) nos oferece uma amostra do discurso da análise. Gilles Deleuze tenta mostrar que todo o tempo "se tratava do simulacro, exclusivamente dos simulacros. Os simulacros implicam essencialmente, sob uma mesma potência, $\mathrm{o}$ objeto $=\mathrm{x}$ no inconsciente, a palavra $=\mathrm{x}$ na linguagem, $\mathrm{a}$ ação $=$ x na história” (1968, p.279). Não poderemos situar o simulacro no drama filosófico de Deleuze na tentativa de mostrar a inversão do platonismo operada pelo próprio Platão 5 . Nos basta expor que o discurso da análise acionado como simulacro é uma contestação do mundo da representação que se baseia tanto na noção de modelo quanto na de cópia, tanto na noção de identidade quanto na de semelhança, tanto na noção de mesmo quanto na de contradição (DELEUZE, 1968, p.65). O discurso da análise é tal qual o simulacro, acionado como potência da divergência e do descentramento e funcionando como sistema diferencial. "O simulacro é o sistema em que o diferente se refere ao diferente por meio da própria diferença", sua unidade de medida é o díspar e sua "convergência é um caos informal que compreende" tudo. Nada goza de um privilégio no sistema. Tudo é diferença nos elementos e diferença de diferença na comunicação deles. "O que se desloca e se disfarça nos elementos que se comunicam não pode e não deve ser identificado, mas existe, age como o diferenciante da diferença”. O discurso da análise é assombrado pelo percussor sombrio, seu sistema de simulacro "interiorizou a dissimilitude de suas séries constituintes, a divergência de seus pontos de vista, de modo que ele mostra várias coisas, conta várias histórias ao mesmo tempo" (1968, p. 73, 260).

A despeito desses balanços, parece que, na cultura francesa, contudo, o discurso da análise não fica muito bem encaixado. Seria a Tríplice Entente, Marx, Saussure e

\footnotetext{
${ }^{4}$ All three - Nietzsche, Freud, Marx - free our horizon for a more authentic speaking, a new reign of truth, not only by means of "destructive" critique but by the invention of an art of interpreting.

${ }^{5}$ Cf. Lógica do Sentido (1968). Principalmente os apêndices sobre Platão e Lucrécio.
} 


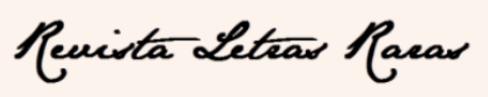

ISSN: $2317-2347$ - v. 8, n. 3 (2019)

Freud, comparável a Marx, Nietzsche e Freud na articulação da história, da linguagem e do sujeito, tal como a técnica interpretação do discurso da análise?

Com efeito, a dissimetria das formas, que acontece no âmbito da linguagem, é suscitada entre Saussure e Nietzsche, mas não da mesma maneira que se opõe Filologia à Linguística ou se opõe o método histórico e comparativo ao método funcional e estrutural. Em toda a França a Linguística Geral gozava de um prestígio inconteste. Ainda que Genealogia da Moral (1887) se pergunte como a ciência da linguagem pode auxiliar na história da moral, a presença de Nietzsche não vem para uma valorização da Filologia como ciência da linguagem, mas pela importância da linguagem para a história da Filosofia. Essa é, ao menos, a percepção da l'analyse du discours. De acordo com Foucault (1966), "a linguagem só entrou diretamente e por si própria no campo do pensamento no fim do século XIX. Poder-se-ia mesmo dizer no século XX, se Nietzsche, o filólogo, não tivesse sido o primeiro a aproximar a tarefa filosófica de uma reflexão radical sobre a linguagem" (1966, p.420). Na cultura francesa não há exclusão de Saussure ou Nietzsche no que se refere à linguagem. Há uma sobreposição dos dois para uma complementação científica e filosófica do saber da linguagem.

No que concerne ao papel do inconsciente, destacado como uma série do simulacro, entre os nomes de Freud e Lacan, pode-se esclarecer, do ponto de vista do sujeito, uma outra particularidade da maneira como que o discurso da análise se manifesta na cultura francesa. $\mathrm{O}$ sujeito no discurso da análise na França está sob a égide do inconsciente. A disputa consiste em definir que tipo de inconsciente esse saber do sujeito do discurso da análise estará submetido, pois os atos conscientes do sujeito foram deixados de lado como resultado de uma psicologia ingênua. Seria preciso situar que, na França, o discurso da análise foi parte de um grande contexto de revolta antiacadêmica contra disciplinas canonizadas, como a Psicologia, a História e a Filosofia (DOSSE, 1991, p.424, 425).

A presença do discurso da análise, em alguns autores, na meditação sobre a interpretação e o prestígio que a Linguística desfrutava em toda a França são aspectos que devem ser ambientados em uma experiência não institucional. "É nesse contexto que as referências a Nietzsche, Marx, e Saussure vão ser operacionais, verdadeiras armas da crítica antiacadêmica contra os defensores da ortodoxia universitária e mandarim" (1991, p. 426). O Collège de France e a École Pratique des Hautes Études 


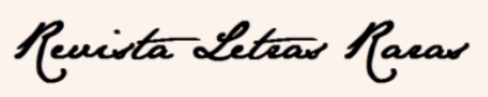

ISSN: $2317-2347$ - v. 8, n. 3 (2019)

eram instituições marginais. Considerando os cursos dados na Sorbonne, em 1967, os professores de Linguística, “com a exceção de André Martinet, eram inteiramente diferentes daqueles que são bem conhecidos hoje. Em 1967, não havia nem um departamento de linguística na Sorbonne, mas somente um simples Instituto de Linguística" (1991, p.425, 426). Embora, no que concerne à Linguística, até hoje, em Paris XVII, ela não possui um curso inteiro, as aulas que o departamento oferece são um complemento para diferentes licenciaturas. Seja como for, a ideia é que, na França, o discurso da análise estava longe do currículo institucional.

\section{Discourse analysis}

Na cultura Anglo-saxã, discourse analysis possui diferentes sentidos históricos. E, para alguns (COULTHARD, 1975), a variedade das acepções, interesses e modelos de discourse analysis aplicados por cada um é tão abrangente, que excluiria qualquer generalização sobre o que teriam em comum. Porém, o discurso da análise é uma técnica de interpretação que está presente no horizonte da discourse analysis, ainda que não possa esgotar a extensão de toda sua experiência cultural, ele é a água que banha as duas grandes margens críticas e não críticas da torrente dessa tradição. De fato, diferente da cultura francesa, o discurso da análise não se apresenta de maneira tão explícita em discourse analysis. É muita mais sutil sua articulação, sendo necessária uma certa conversão do olhar e da atitude para poder reconhecer e considerar o discurso da análise em si mesmo.

Os lados crítico e não crítico da discourse analysis poderiam igualmente articular o discurso da análise se, e somente se, fosse possível aceitar que a situação, as propriedades funcionais faladas e o conhecimento de mundo (SINCLAIR; COLTHARD, 1975, 1992) se atualizassem no lugar do social, das propriedades funcionais textuais e da competência comunicativa (FOWLER et al., 1979). Tanto a British classroom discourse analysis quanto a critical linguistics se servem da interpretação de que "a forma singular do sistema gramatical da linguagem é relacionada com as necessidades sociais e pessoais que são supridas pela linguagem"6

\footnotetext{
${ }^{6}$ The particular form taken by the grammatical system of language is closely related to the social and personal need that language is required to serve.
} 


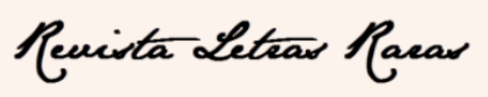

ISSN: $2317-2347$ - v. 8, n. 3 (2019)

(HALLIDAY, 1970, p.142). As duas tradições marcam que "assim como na sociolinguística, a ênfase passou das sentenças abstratas, formais e inventadas para o uso real da linguagem no contexto social"7 (VAN DIJK, 1988, p.21). No entanto, a versão crítica da discourse analysis é uma amostra da fala analítica mais adequada aos termos de uma técnica de interpretação, uma vez que a vertente não crítica se aproxima de uma prática voltada para construção de gramáticas, livro didático de língua, metodologia de ensino de língua estrangeira etc. As limitações da British classroom discourse analysis "são a ausência de desenvolvimento de uma orientação social para o discurso e a insuficiente atenção à interpretação" (FAIRCLOUGH, 1992, p.34). Language as Ideology (1979) passou adiante que teorizar possui um efeito social, deixou como herança a problemática de que a linguística precisa ser "socially responsive". A abordagem "se baseia na obra de Marcuse (e na tradição marxista e hegeliana por meio dele) e na obra de Freud. Subjacente a essa abordagem da linguagem está a suposição de que os itens e processos da linguística fazem parte de sistemas ordenados", (HODGE; KRESS, 1979, p.151). Como professores, Gunther Kress e Bob Hodge ensinaram Linguística e Literatura com uma "estrutura teórica abrangente de Marx e Freud e Whorf e Halliday" 9(KRESS 2008, apud LINDSTRAND, 2008, p.61).

Em Prejudice and Discourse (1984), o foco eram as características do discurso da fala preconceituosa. Os seus aspectos sociais e psicológicos seriam menos evidenciados, mas o projeto de Teun Van Dijk (1984) estava interessado "principalmente pelas relações entre o discurso, por um lado, e o contexto cognitivo e social do uso da linguagem, por outro" ${ }^{10}$ (1984, p.ix). As três funções de Halliday (1970) eram correlatas da estrutura da frase em língua inglesa ou mesmo de um speech act ou texto. Em Van Dijk (1984), elas estão relacionadas às maneiras como a conversa quotidiana e outros tipos de discurso expressam "prejudice talk", considerada também como um tipo de texto. A despeito disso, o discurso da análise adquiria a conotação de

\footnotetext{
7 Just as in sociolinguistics, the emphasis thus shifted from abstract, formal and invented sentences to real language use in the social context.

${ }^{8}$ Our approach draws on the work of Marcuse (and through him on the Marxist and Hegelian tradition) and that of Freud. Underlying our approach to language is the assumption that linguistics items and processes as part of ordered systems.

9 Overarching theoretical frame of Marx and Freud and Whorf and Halliday".

10 primarily interested in the relationships between discourse, on the one hand, and the cognitive and social context of language use, on the other hand.
} 


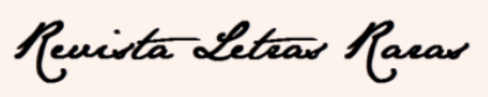

ISSN: $2317-2347$ - v. 8, n. 3 (2019)

que "tanto a pesquisa quanto a ação sociopolítica podem fornecer insights e mudanças na natureza racista de nossas sociedades"11 (1984, p.154).

Já em News as Discourse (1988) a ênfase acontece no âmbito dos processos cognitivos. Na obra se nota que "várias estruturas da notícia estão sistematicamente relacionadas às condições cognitivas e sociais da sua produção [...] Sua base teórica deriva dos avanços atuais no processamento de textos dentro da psicologia cognitiva e da Inteligência Artificial ${ }^{12}$ (VAN DIJK, 1988, p. vii, viii). A cognição, no entanto, como está ligada à ideologia, não se restringe à psicologia do indivíduo, ela repete as estruturas sociais. O discurso da análise, no livro de Van Dijk, apresenta-se como uma “descrição das dimensões cognitivas, sociais e culturais do uso da linguagem e do discurso" 13 (1988, p.23). O saber histórico é dividido entre um contexto social micro e um contexto cultural macro. "Pretende-se também preencher a lacuna entre os microníveis e macroníveis da análise das notícias e entre textos da mídia e os contextos"14 (1988, p.181). Assim o saber histórico do discurso da análise se realiza em discorse analysis como uma dimensão social e cultural, examinando o "que a filiação ideológica, grupos, relações grupais, interesses, poder ou domínio significam"15 (VAN DIJK, 1988, p.136). Sendo o social uma outra dimensão do saber do sujeito, ao lado da Psicologia cognitiva.

A fala analítica da maneira como demarca presença em discourse analysis é delineada por ênfases distintas nos enunciados de sua composição, apesar da aceitabilidade pelo todo. A gramática funcional da linguagem e a psicologia cognitiva do sujeito se destacam na técnica de interpretação da fala analítica em discourse analysis, mas o social é o carro chefe de Language and Power (1988). Norman Fairclough distinguia três dimensões para analisar o discurso de uma maneira crítica. Havia a descrição formal do texto, na qual se faz referência às propriedades funcionais da linguagem, à maneira de Halliday. Depois, havia a fase da interpretação que se concentrava no "relações entre eventos sociais transitórios e estruturas sociais mais

\footnotetext{
${ }^{11}$ Both fundamental research and sociopolitical action may provide insights into, and changes of, the racist nature of our societies.

${ }^{12}$ various structures of the news are systematically related to the cognitive and social conditions of news production. [...] Their theoretical basis derives from current advances in text processing within cognitive psychology and Artificial Intelligence

13 description of cognitive, social, and cultural dimensions of language use and discourse.

${ }^{14}$ It is also intended to bridge the gap between the microlevels and macrolevels of news analysis and between media texts and contexts.

${ }^{15}$ What ideological membership, groups, group relations, interests, power or dominance mean.
} 


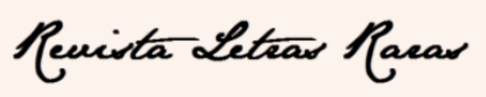

ISSN: $2317-2347$ - v. 8, n. 3 (2019)

duráveis que moldam e são moldadas por esses eventos" "16 (FAIRCLOUGH, 1988, p.27). Todavia, parece até mesmo que a presença de uma Psicologia, de uma valorização da consciência no âmbito do saber do sujeito, somente se justifique tendo em vista que ela é o primeiro passo na direção da emancipação do estado de dominação de algumas pessoas sobre outras dentro do "social struggle" que the dá sentido. "O indivíduo é capaz de agir apenas à medida em que existem convenções sociais para agir ao seu alcance [...] ser socialmente restrito não exclui ser criativo"17 (FAIRCLOUGH, 1988, p.28).

É de se considerar que a fala analítica está presente nas três funções da linguagem de Discourse and Social Change (1992) que são dimensões de sentido que coexistem e interagem em todo discurso. Em primeiro lugar, "a função identitária se relaciona com o modo pelos quais as identidades sociais são estabelecidas”. As identidades são "posições de sujeito" e "tipos de "eu"”. Em segundo lugar, a função relacional serve para construir as "relações sociais entre as pessoas". As relações são representadas e negociadas. Enfim, em terceiro plano, "a função ideacional relaciona os modos pelos quais os textos significam", como contribuem para a "construção de sistemas de conhecimento e crença" (FAIRCLOUGH, 1992, p.91,92).

O discurso da análise aparece como técnica de interpretação e como característica constitutiva do objeto que serve tanto para reproduzir como para transformar a sociedade. "Ao enfocar a mudança social, essa versão da CDA é histórica. [...] Para perseguir esse objetivo, é necessário concentrar-se na mudança social que se baseia nas crises e transformações do capitalismo em nossos tempos, o presente e o passado recente" ${ }^{\prime 18}$ (FAIRCLOUGH, 2014, p.32).

Há o costume de relacionar discourse analysis à filosofia analítica, à linguística crítica e os estudos culturais. A aproximação com esse último movimento, contudo, não se dá apenas pela preocupação com a mudança social e pelo destaque da escolha da mídia como objeto de estudo e crítica, mas pelo próprio discurso da análise. O liame entre os estudos culturais e discourse analysis é sustentado pela fala analítica. No

\footnotetext{
${ }^{16}$ Relationships between transitory social events and more durable social structures which shape and are shaped by these events.

${ }^{17}$ The individual is able to act only in so far as there are social conventions to act within [...] being socially constrained does not preclude being creative.

${ }^{18}$ In focusing upon social change, this version of CDA is historical. [...] To pursue this objective, it needs to focus upon social change which is grounded in the crises and transformations of capitalism in our own times, the present and the recent past.
} 


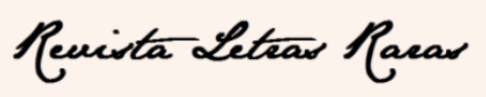

ISSN: $2317-2347$ - v. 8, n. 3 (2019)

pequeno ensaio The Question of Cultural Identity (1992), a presença do discurso da análise se faz notar como se fosse parte dos grandes avanços na teoria social e nas ciências humanas, apresentados por Stuart Hall como responsáveis pelo descentramento final da identidade moderna, o deslocamento do sujeito cartesiano. O primeiro deslocamento se refere ao pensamento marxista, em especial pela via aberta por Louis Althusser. O segundo grande descentramento foi a descoberta do inconsciente por Freud, com destaque para a renovação lacaniana. O terceiro deslocamento estaria associado ao nome de Saussure (1992, p.35-40).

$\mathrm{Na}$ avaliação geral da presença do discurso da análise na cultura anglo-saxã, podemos perceber que discourse analysis, ao contrário da linguística crítica e dos estudos culturais, não se utiliza da Psicanálise na sua técnica de interpretação. A consciência como enunciado de uma Psicologia cognitiva é a técnica para interpretar a dimensão do saber do sujeito no seu discurso da análise. É creditado à visão psicanalítica "uma posição do sujeito como um efeito" e como resultado, para discourse analysis se negligência "a capacidade dos sujeitos de agirem como agentes" (FAIRCLOUGH, 1992, p.55, 56). Esse é um ponto que difere a fala analítica da discourse analysis e da l'analyse du discours, porque na versão francesa a consciência perde espaço para o inconsciente. Um outro aspecto de divergência se refere à dimensão da linguagem. Se l'analyse du discours estabelecera um projeto que fundamentava seu estudo da linguagem em modelos baseados na langue saussuriana e no questionamento de Nietzsche sobre a gênese da verdade, discourse analysis o complementava com a parole e com o speech act da filosofia analítica, com as funções culturais de Malinowski e as funções linguísticas do Círculo de Praga contidas em Halliday. No âmbito do saber da história, em discourse analysis, o materialismo histórico se refere mais a Antônio Gramsci do que a uma leitura de Althusser. Porque as ações que vão transformar a sociedade do capitalismo para o socialismo não devem ser empreendidas diretamente pelo Estado, nem contra ele. Elas devem ser indiretas, como no caso da intepretação, a qual ninguém deve se furtar de investir como uma prática orientada politicamente.

\section{Doutrinas do discurso}




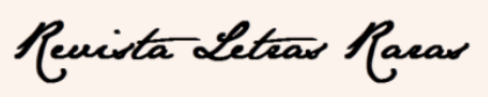

ISSN: $2317-2347$ - v. 8, n. 3 (2019)

No Brasil, a fala analítica se fez presente nas doutrinas do discurso, em um ou outro artigo publicado em revista ou mesmo em algumas teses e dissertações. Existiram várias tentativas de busca por uma técnica de interpretação para a questão do discurso ao longo das décadas de setenta, oitenta e noventa do século passado no Brasil. Nem todas as doutrinas tiveram a presença do discurso da análise como técnica para o exercício de sua interpretação. As amostras que se seguem sim.

Uma amostra do discurso da análise na cultura brasileira se deu com Oswald de Andrade (ca. 1952-1953). Mas a tríade primitivista, Marx, Freud e Nietzsche, não era articulada em função de uma doutrina do discurso, ela fazia parte de uma interpretação da história das ideias. Oswald de Andrade, ao longo de suas exegeses históricas, mostra rupturas em diferentes ciclos e afirmaria que cada ciclo conduz em si a sua própria subversão. Os ciclos históricos operam por rupturas, que se processam por contradições e não caminham numa reta ascensional. É impossível continuar um quadro de evolução das ideias sem dar atenção a todas as transformações que separam um e outro ciclo. Os ciclos históricos têm se sucedido e se revezado entre si com características que os separam nitidamente, e é a contradição que existe na raiz desse movimento. Uma ruptura forte e decisiva seria o sinal de uma exigência anterior imposta por negação. Era uma acepção cíclica da história a qual passava por estados que apareciam e desapareciam em um movimento que qualquer fase podia tornar a reaparecer. Havia a tese de que a humanidade passou por uma primitiva fase geral e o discurso da análise seria responsável por minar o mundo do patriarcado, abrindo a possiblidade de retorno do costume primitivo que seria o matriarcado envolto na economia do ser, no direito da guerra e na moral da liberdade. Portanto, para a filosofia da história antropofágica (MARCELINO, 2013), era o discurso da análise responsável pelo retorno cíclico dos começos.

No início da década de setenta, Carlos Henrique Escobar (1971) procurava estabelecer uma Ciência dos Discursos Ideológicos por meio de uma leitura do corte produzido pela "tríade Marx/Freud/Saussure". Na transição da década de sessenta para setenta, em ensaios publicados como capítulo de livro e em diferentes artigos na revista 


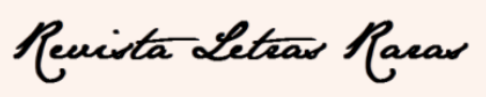

ISSN: $2317-2347$ - v. 8, n. 3 (2019)

Tempo Brasileiro e na Revista de Cultura Vozes ${ }^{19}$, há uma transformação radical da Psicanálise e da Linguística, no esforço de produção teórica da região dos discursos ideológicos no continente histórico. "Tudo isso se passa institucionalmente no Rio de Janeiro, na cadeira de Semiologia e Epistemologia da Comunicação, na Escola de Comunicação da UFRJ, e na cadeira de Fundamentos Científicos da Comunicação Social do Instituto de Arte e Comunicação Social da UFF". A formação dos trabalhos de Escobar em torno de uma doutrina do discurso é marcada pela presença da fala analítica em um momento "militante" "como forma de intervenção teórica e política", não apenas como esquema de enunciados de uma técnica de interpretação. “A problemática gira em torno da existência, em Saussure, de uma Semiologia que possibilita a construção de um campo maior e interdisciplinar (Psicanálise, Linguística e História) para a compreensão da produção/circulação dos discursos" (KOGAWA, 2012, p.49, 197).

O livro A Metamorfose do Silêncio: Análise do Discurso Literário (1974) se instala no rol de contribuições para as doutrinas do discurso. Luiz Costa Lima se destaca por utilizar a fala analítica por onde fluem os analistas, críticos e historiadores da literatura. Isso lhe parecia decisivo para a estética na análise do discurso literário. A fala analítica seria para ele a única maneira de "destronar a concepção antropocêntrica", da qual participava a estética, por "incentivar a análise sistêmica". "Desde Marx, Freud e Saussure, irmanados como fundadores da teoria dos sistemas sociais, o homem já não aparece como senhor de suas criações. É antes um eficiente carteiro, que entrega a correspondência cujo conteúdo desconhece" (COSTA LIMA, 1974, p.40). A doutrina do discurso para Costa Lima pertencia ao campo das ciências sociais e a ideia de sistema funcionaria para as ciências sociais como a concepção de Galileu funcionou para ciências exatas (COSTA LIMA, 1974, p.40).

A ideia sistêmica contida no discurso da análise para revolucionar a estética não se apresentou, porém, na técnica de interpretação de Costa Lima com o nome de Marx. Antes, seria da "confluência primeira entre o estabelecimento da Linguística e da Psicanálise, mediada pela obra de Lévi-Strauss" (COSTA LIMA, 1974, p.17), que deriva a sua possibilidade de estabelecimento de uma doutrina do discurso. Mas como não considerar a ausência de Marx como um fator de desequilíbrio no argumento?

\footnotetext{
19 Para uma referência mais completa dos trabalhos e uma análise do papel olvidado de Escobar na recepção de Pêcheux. Cf. (MOTTA, 2011) (KOGAWA, 2012).
} 


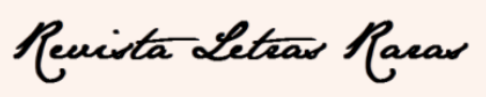

ISSN: $2317-2347$ - v. 8, n. 3 (2019)

Porque o lugar que Marx cede a Lévi-Strauss, em A Metamorfose do Silêncio, dá-se no âmbito da história que, como na tese de doutorado em teoria literária de Costa Lima, Estruturalismo e Teoria da Literatura (1973), "determina uma situação antropológica", que "não se confunde com o campo ocupado pela ciência da antropologia" (1973, p.217). Para ver isso seria preciso recuar no ensaio Pressupostos do Pensamento Estruturalista (1971). A partir da introdução do conceito de história cumulativa de Lévi-Strauss, em Race et Histoire (1952), Costa Lima demonstra como ele difere do conceito de história linear e evolucionista de Augusto Comte. Sem, contudo, desconsiderar que a problemática da natureza e da cultura era muito mais frequente do que o conceito de história que se discutia com um valor metodológico. Mas no conceito de história cumulativa já aparecia o que Lévi-Strauss havia dito das relações entre natureza e cultura. O mito era "confundido com a própria reflexão que se faz das representações sociais". "A história, portanto, não nos dá estruturas, ela se nos dá com estruturas" (COSTA LIMA, 1971, p.77, p.98). Mas isso lhe servia porque comunista é algo que nunca foi, nem marxista. Daí toda sua insatisfação do tratamento dado ao realismo por Lukács, para quem se Tolstoi é superior a Zola é porque soube desafiar a náusea trazida pela curva da história, o que seria tão estreito quanto o realismo socialista que havia combatido.

A partir de uma disciplina diferente, encontramos o discurso da análise em uma tese de doutorado, desta vez no departamento de Sociologia da USP. Em A ideologia Curupira: Análise do Discurso Integralista (1977) de Gilberto Vasconcellos, história e inconsciente andam entrelaçados para interpretar aquilo que denominou de discurso integralista. O materialismo histórico e a psicanálise são patentes, Freud e Marx são nomeados, ao contrário de Saussure. Muito embora havendo a ocorrência de princípios da Linguística, como nas intepretações sobre o enunciado, o desvio semântico, o léxico, a relação intrínseca entre significante e significado no discurso literário, a ornamentação retórico-linguista e as proposições significativas. A tese possuía como técnica de interpretação o pressuposto que, mesmo nem sempre expressamente enunciado, "a leitura ideológica de um texto deve se ater mais a sua camada latente do que a sua camada manifesta" como, por exemplo, a ausência da classe operária de fato, mas presente no discurso integralista (VASCONCELLOS, 1977, p.197). O que há de mais especial é a interpretação e a atenção à configuração linguística da ideologia, que se 


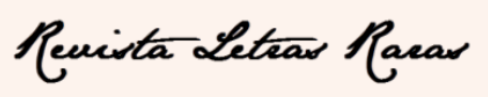

ISSN: $2317-2347$ - v. 8, n. 3 (2019)

nota pela afirmação da afinidade entre linguagem e ideologia, pois o discurso se confundiria com a teoria que antecede a prática política.

Para Florestan Fernandes (1978), a contribuição da tese de Vasconcellos é menos histórica que teórica e integra o corpus da Sociologia da Dependência. Mas o que tem isso a ver com Sociologia da Dependência? Continuando a tradição de alguns membros da Escola de Recife, a teoria da dependência, recorrente em autores como Fernando Henrique Cardoso, Roberto Schwarz e Florestan Fernandes, substitui a causa Biológica da dependência ou imitação pela causa econômica. Vasconcellos faz com que a teoria da dependência saia do campo econômico para "entender e desentranhar os processos culturais" até então inexplorados do Brasil moderno. O "propósito era estudar o discurso Integralista como ideologia fascista sob o ponto de vista de sua recepção mimética e caricata em países colônias ou periferias". Mas se "estava menos interessado no fascismo propriamente dito do que na patologia da imitação cultural em um país que é satélite das metrópoles imperialistas" (VASCONCELLOS, 2010, p.13).

Na revista Série-Estudos, do curso de Letras do Centro de Ciências Humanas e Letras das Faculdades Integradas de Uberaba, Eni Orlandi (1981) apresentava a articulação de três regiões do conhecimento científico: o materialismo histórico, a Linguística e uma teoria da subjetividade, de natureza psicanalítica, como quadro epistemológico de uma doutrina do discurso também denominada "análise do discurso (AD)". Em sua interpretação, "Marx, Nietzsche e Freud são fundadores de discursos, não apenas autores" (ORLANDI, 1993, p.24). Ela assumia tal perspectiva para interpretar o discurso pedagógico, o discurso da história, o discurso da educação indígena, a argumentação, o discurso religioso etc. como objetos provisórios para reflexão da experiência da linguagem. Partindo de um território que possuía a linguagem como objeto de estudo, a finalidade era "incorporar as noções de social e história" e "questionar a consciência" nesse campo. O discurso da análise era visto como uma interpretação privilegiada para a linguística investigar os processos históricos-sociais que entram em jogo na constituição da linguagem. E "deriva daí a possibilidade de se apreender a ilusão subjetiva que muitas vezes está fletida, e não criticada, nas teorias linguísticas” (ORLANDI, 1983, p.18, 19).

Ao longo da década de oitenta, o discurso da análise foi acionado nos cursos de Letras, sobretudo, para a interpretação do discurso pedagógico, no ensino de línguas na 


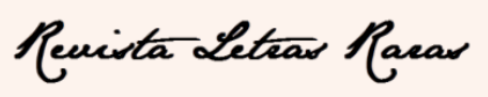

ISSN: $2317-2347$ - v. 8, n. 3 (2019)

escola, notadamente, na prática de leitura. Era a esse recorte que o discurso da análise daria atenção na reflexão sobre a educação. A fala analítica também auxiliava na interpretação de um outro aspecto do discurso pedagógico, o discurso autoritário. Nessa fase, a noção de leitura ganhou sentido nas doutrinas do discurso por causa das suas grandes implicações para o ensino de línguas e a alfabetização. Com essa experiência no ensino de leitura que algumas condições foram dadas para que a interpretação e a compreensão fossem formadas nas doutrinas do discurso. Um outro exemplar de doutrina do discurso, no qual ensino e leitura se relacionam com a fala analítica, pode ser encontrado na tese Discourse Analysis and Syllabus Design: An Approach to the Teaching of Reading (1986). A tese de Moita Lopes recorre a uma doutrina do discurso para equipar professores com um currículo voltado para uma prática de leitura. A acepção de linguagem adotada é interacional, acontece entre os participantes, leitor e escritor, no discurso, através do seu triplo aspecto sociolinguístico e sociopsicológico. A linguagem é um sentido negociado em uma interação comunicativa. "O leitor nesse processo está interagindo com o escritor, por assim dizer, a fim de negociar o significado do texto"20 (MOITA LOPES, 1986, p.109). E é na filosofia da educação que se vai buscar o saber da história, concebida em um sistema imperialista que, por meio da colonização intelectual e técnica, controla o poder de uma sociedade. O sujeito do sistema histórico age conscientemente escolhendo as alternativas que o mundo oferece. Ele é o agente, não o objeto da história, possuindo uma missão ontológica, a qual como indivíduo influencia criticamente na transformação da sociedade, rompendo com a psicologia da dependência (1986, p.22, 49, 74).

Da própria tradição semântica dos anos sessenta, Milton José Pinto (1937-2011) agrega à semiologia uma doutrina social dos discursos, ao se informar do estruturalismo linguístico, do marxismo e da psicanálise (PINTO, 1999). A fala analítica foi responsável por substituir a Semiologia no seu percurso intelectual nas doutrinas do discurso ou, como Milton José Pinto preferiu chamar, Semiologia dos Discursos Sociais (1995). A análise do discurso é, segundo Pinto (1999), um dos setores de pesquisa no campo da Comunicação que mais vem se desenvolvendo desde a década de oitenta. Como lecionou no departamento de Letras da PUC-Rio entre 1971 e 1988 e na Escola de Comunicação da UFRJ de 1970 a 2009, a distância entre Linguística e Comunicação

${ }^{20}$ The reader in this process is interacting with the writer, so to speak, in order to negotiate the meaning of the text. 


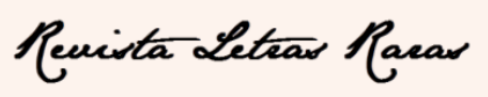

ISSN: $2317-2347$ - v. 8, n. 3 (2019)

não é longa, ou, pelo menos, não é do modo como ele trabalha. Apesar de tratar, no começo, de uma teoria semântica do discurso literário e das línguas naturais, não tratava do ponto de vista do linguista, mas do semiólogo debruçado pelo devir das significações. Seu projeto tomava uma doutrina do discurso para a interpretação de qualquer sistema semiótico que se apresente empiricamente em uma língua natural ou sobre os elementos da imagem nos diferentes meios de comunicação (PINTO, 1971, p.10).

Nesse caso, a fala analítica se manifestou em uma doutrina de discurso que contribuiu com a prática de interpretação da imagem. Embora Milton José Pinto fosse formado na tradição semântica de estudos da linguagem, não usava a Linguística como um instrumento para trabalhar com a análise de textos e os preceitos da semiologia e da semiótica no estudo das imagens. Por isso Semiologia dos Discursos Sociais, no plural, por trabalhar com meios de comunicação, interessou-se pelo estudo da imagem, mais precisamente pelas relações entre texto e imagem. Para interpretar as relações entre sistemas semióticos diferentes, o discurso da análise foi estabelecido sob três postulados (PINTO, 1988), cada qual derivado de uma região do seu saber e embasado por uma teoria da comunicação social. O primeiro postulado, o postulado da semiose infinita, dá conta do saber da linguagem. Qualquer objeto, verbal ou não verbal, é sempre semantizado em uma cultura. Seu funcionamento ocorre segundo a sua qualidade de ser um ponto de cruzamento, isto é, um lugar de transição constituído por uma série de objetos significantes em um processo de produção de sentido, onde um discurso se encontra relacionado a outros, remetendo-se uns aos outros ad infinitum. O postulado da economia política do significante se relaciona com à história. Para significar qualquer objeto entra num processo de comunicação/troca produzido em um contexto histórico. O processo desse fenômeno de comunicação passa pela produção, circulação e consumo de sentido, estabelecendo as determinações responsáveis pela sua escolha e aquelas responsáveis pela sua restrição. A relação do discurso com as determinações responsáveis pela escolha de sentido configura a ideologia; as determinações responsáveis pela restrição de sentido configuram o poder. Por fim, o postulado da heterogeneidade enunciativa se refere ao sujeito. O postulado questiona a unicidade do sujeito por meio do sujeito anônimo, pelo sujeito plural e pelas evidências estratégicas de se mostrar o outro, a partir das manifestações empíricas da cultura. Os receptores e 


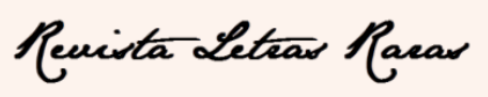

ISSN: $2317-2347$ - v. 8, n. 3 (2019)

emissores reais podem assumir lugares idealizados como sujeito da enunciação, do enunciado e sujeito falado, todos modulados como intenções comunicativas ritualizadas, conscientes e/ou não.

Antes de concluirmos, não se pode deixar de mencionar como as revistas de cultura foram publicações que tiveram um papel fundamental para a formação do discurso da análise. Eram revistas que circulavam no contexto de uma imprensa que não exercia mais a sua prática através da crítica. Concorriam com uma imprensa fundamentada na prática de reportagem, auxiliada pela disseminação das revistas ilustradas e principalmente pela televisão. Nem ao menos se pode falar em concorrência desleal. Não havia concorrência entre as revistas de cultura e os produtos da imprensa ilustrada, radiofônica e televisiva. No entanto, as revistas culturais, não relacionadas institucionalmente às universidades, Revista de Cultura Vozes ${ }^{21}$ (1907), Revista Tempo Brasileiro $^{22}$ (1963), Revista Civilização Brasileira (1965-1968) ${ }^{23}$ etc. preencheram um espaço que viria a ser ocupado apenas com a consolidação dos programas de pósgraduação, cada qual com sua produção impressa que, além de congressos, seminários etc., seriam o principal meio de publicação. Livros quase inteiros foram reuniões de artigos desse ambiente que se criou a partir da pós-graduação, como os primeiros escritos de Eni Orlandi e Moita Lopes.

Formado a partir de um código específico de conduta, o discurso da análise, ao lado da imprensa, também esteve muito próximo da prática pedagógica de nível superior. Isso é resultado do fato de que todos que praticaram o discurso da análise eram professores. Inevitavelmente, introduziram a técnica de interpretar inclusa nos seus escritos na atividade de lecionar. Na década de setenta e oitenta, há evidências de cursos de graduação e pós-graduação com disciplinas que lançavam mão do recurso interpretativo do discurso da análise, como Pinto e Escobar, sob o baluarte direto de uma doutrina do discurso. Assim como há evidências, na década de noventa, de grupos de trabalho em congressos da área de Comunicação, como a COMPÓS, exclusivos para doutrinas do discurso, dos quais alguns lidavam com a fala analítica.

\footnotetext{
${ }^{21}$ A revista é um periódico mantido por uma editora católica com ligação com a Teologia da Libertação, mas não publica apenas textos de teor religioso ou comprometidos com a Igreja (SPRÍCIGO, 1998).

${ }^{22}$ A revista pertence a editora criada por Gustavo Barroso, Civilização Brasileira, e foi dirigida por Ênio Silveira. No primeiro número, indica que se ocupará do "terreno dos estudos políticos, sociológicos, econômicos e culturais" (CAMARGO, 2010).

23 A revista e a editora Tempo Brasileiro foram fundadas por Eduardo Portela, crítico literário, professor de Cultura Brasileira da UFRJ (CAMARGO, 1997).
} 


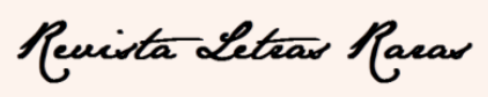

ISSN: $2317-2347$ - v. 8, n. 3 (2019)

\section{Conclusão}

A presença do discurso da análise, como acabamos de ver acima, ao longo das décadas de cinquenta, setenta, oitenta e noventa, entre nós, foi verificada em diferentes territórios, como na Antropofagia, com sua interpretação da filosofia da história, no Marxismo, com sua interpretação política, na Sociologia, com sua interpretação ideológica, na Literatura, com sua interpretação estética, na Linguística e na Linguística Aplicada, com uma interpretação pedagógica e na Comunicação, com uma interpretação semiológica e semiótica. Com exceção do primitivismo oswaldiano, a fala analítica foi acionada nesses territórios sempre como parte integrante de uma doutrina do discurso.

Nos remetendo ao objetivo principal de conceituar o discurso da análise nas culturas investigadas, percebemos a articulação de três enunciados - linguagem, história e sujeito. É uma técnica de interpretação que vemos se manifestar na segunda metade do século XX entre as doutrinas do discurso, mas que existem condições de se demonstrar que ela possui um passado entre nós. Vimos, ao longo do texto, que a formação recente do discurso da análise no Brasil traz evidências que o saber do sujeito aceita um espectro maior de enunciados, englobando vertentes psicológicas e psicanalíticas. O que é um divisor de águas para as linhas estrangeiras. É digno de nota que o marxismo presente em discourse analysis e l'analyse du discours não encobre por completo as doutrinas do discurso no seu saber histórico. No tocante ao saber da linguagem, as tradições francesa e anglo-saxã não se encontram alinhadas com enunciados do saber da história e do sujeito, quando assumem tons semióticos e semiológicos. A l'analyse du discours, quando munida de conteúdo semiológico, ausenta-se do discurso da análise, por não investir na interpretação histórica, como em Patrick Charaudeau. Isso não acontece com Milton José Pinto, que sempre alinha uma visão semiótica e semiológica com enunciados do saber da história e do sujeito. É preciso ter em mente que, no Brasil, nas décadas de setenta, oitenta e noventa, também houve diversas tentativas de formular uma doutrina do discurso, as quais muitas, diferentes das quais mostramos, não continham o discurso da análise. Mesmo no percurso de cada uma das amostras mencionados, o discurso da análise se dá em graus distintos de articulação, às vezes, 


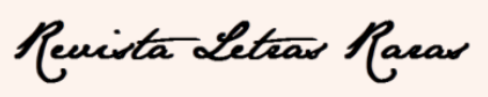

ISSN: $2317-2347$ - v. 8, n. 3 (2019)

presente, mas com um encaixe truncado ou com ênfase desproporcional, que somente viria a se refinar com o decorrer das publicações em teses e revistas.

Muito diferente do que pode hoje em dia algum aluno da graduação espontaneamente identificar, as doutrinas do discurso, para os projetos da segunda metade do século XX, eram relacionadas, no estrangeiro, aos nomes de Derrida, Foucault, Althusser, Barthes, Lévis-Strauss, Greimas, Pêcheux, Harris, Halliday, Verón, Widdowson etc. Todos, de alguma forma, eram figuras situadas na família das doutrinas do discurso. No entanto, as condições para que a fala analítica se tornasse uma técnica de interpretação das doutrinas do discurso entre nós não devem ser buscadas inteiramente em uma cultura estrangeira. A fala analítica pode ser identificada facilmente como técnica de interpretação das doutrinas do discurso. E as doutrinas do discurso são consideradas herdeiras da discourse analysis e da l'analyse du discours. $\mathrm{O}$ que resulta inferir que o discurso da análise é uma influência estrangeira. Partindo da hipótese que, ao final do século $\mathrm{XX}$, o discurso da análise não é uma influência estrangeira que se manifesta nas doutrinas do discurso, ao contrário, ele reforça uma tendência antiga e uma articulação consumada, colocaríamos a questão de se a fala analítica das doutrinas do discurso marcaria uma passagem epistemológica autônoma ou ruiria sob uma retrospectiva. Sugerimos investigar sob que condições o discurso da análise se tornou objeto de um saber e entre que limites se desdobra seu domínio epistemológico na cultura brasileira. A pesquisa que se abre a partir da conceituação do discurso da análise não pode mostrar a sua repetição idêntica em todas as épocas passadas da cultura brasileira. Nem aceitar que o discurso da análise é uma influência estrangeira do final do século XX. As pesquisas futuras devem seguir na direção de caracterizar as condições de possibilidade que garantiram a repetição do discurso da análise de maneiras diferentes, através de subsídios de alguns deslocamentos epistemológicos que a técnica de interpretação sofreu no passado, até tomar a feição que ela possui hoje no Brasil.

O valor do presente escrito não está em refazer passo a passo a história do tema, mas em trazê-lo à tona e assinalar alguns pontos notáveis das condições em que ele é possível. A serventia, portanto, está em despertar para a questão em si e fornecer apontamentos para outras iniciativas de pesquisa a partir da temática geral do discurso da análise, que não é mais do que o produto da formação histórica que liga a 


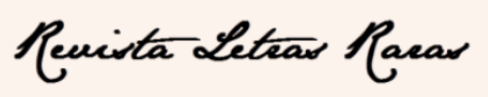

ISSN: $2317-2347$ - v. 8, n. 3 (2019)

interpretação e o saber da linguagem. Uma história que "nos cerca e nos delimita; não diz o que somos, mas aquilo que estamos em vias de diferir". A história possibilita algo que lhe escapa (DELEUZE, 1992, p.119, 210). Avaliar a tentativa de atualização que as doutrinas do discurso tentaram fazer com a fala analítica levanta a investigação de uma experiência da qual o presente se distancia inevitavelmente. Estamos diante dessa fatalidade.

\section{REFERÊNCIAS}

ALTHUSSER, L. [1964] Freud e Lacan. Marx e Freud: introdução crítica-histórica. Rio de Janeiro, Graal, 1985. janeiro, Graal, 1980.

[1969] Nota ao editor a "Freud e Lacan". In. Posições-2. Rio de

CAMARGO, M. Resistência e crítica: Revistas Culturais Brasileiras nos tempos da Ditadura. Boletim de Pesquisa NELIC, v. 10 n. 15, Florianópolis, 2010.

Tempo Brasileiro e Novos Estudos nos anos 80. Boletim de Pesquisa NELIC, v. 1 n. 1, Florianópolis, 1997.

COSTA LIMA, L. Estruturalismo e teoria da literatura. Petrópolis; Vozes, 1973. . As metamorfoses do silêncio: análise do discurso literário. Rio de Janeiro; Eldorado, 1974.

. [1971] Pressupostos do Pensamento Estruturalista. In. FOUCAULT, M. et al. Estruturalismo e Teoria da Linguagem. Petrópolis, Vozes, 1974.

COULTHARD, M. Introduction to Discourse Analysis. University of Michigan, 1975. . Towards an analysis of discourse. In. COULTHARD, M. Advances in Spoken Discourse Analysis. London, Routledge, 1992.

DELEUZE, G. [1968] Diferença e repetição. Rio de Janeiro, Graal, 1988. . Conversações, 1972-1990. São Paulo, Ed.34, 1992.

DOSSE, F. [1991] História do Estruturalismo, V. I. O campo do signo 1945-1966. São Paulo, Editora da UNICAMP, 1993.

ESCOBAR et al. Epistemologia e Teoria da Ciências. Petrópolis; Vozes, 1971.

FAIRCLOUGH, N. [1992] Discurso e mudança social. Brasília, Editora da UNB, 2001. . Language and Power. New York, Longman, 1984. . [2014] What is CDA? Language and Power Twenty-Five Years On.

Disponível em:

http://www.academia.edu/8429277/What_is_CDA_Language_and_Power_twenty five_years_on. Acesso em 16/04/ 2016. 


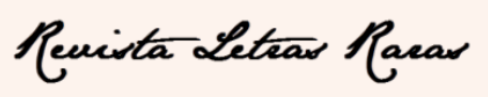

ISSN: $2317-2347$ - v. 8, n. 3 (2019)

FERNANDES, F. [1978] Prefácio. In. VASCONCELOS, G. Ideologia Curupira. Análise do discurso Integralista. São Paulo; Editora Brasiliense, 1979.

FOWLER, R et al. Language and Control. London: Routledge, 1979.

FOUCAULT, M. [1966] As palavras e as coisas. São Paulo: Martins Fontes, 2002.

Martins Fontes, 2008. [1964] Nietzsche, Freud e Marx. In Ditos e Escritos II. Rio de Janeiro, . [1977] Verité et pouvir. In. L'Arc, nº70, 1977. In. Microfísica do poder. Rio de Janeiro; Graal, 2010.

HALL, S. The Question of Cultural Identity. In. HALL, S et al., (eds.) Modernity and its Futures. Cambridge: Polity, 1992.

HALLIDAY, M. Languages structure and language function In. LYONS, J. New horizons in linguistics. Peguin, Harmondsworth, 1970.

HYPOLLITE, J. [1966] A estrutura da linguagem filosófica no "prefácio" da fenomenologia do espírito, de Hegel. In. MACKSEY, R. DONTO, E. A controvérsia estruturalista. São Paulo, Cultrix, 1976.

KOGAWA, A. [2012] Linguística e Marxismo. Condições de Emergência para um Análise do Discurso Francesa no Brasil. São Paulo, FAP-UNIFESP, 2015.

KRESS, G. HODGE, B. Language as Ideology. London, Routledge \& Kegan Paul Ltd. 1979.

KUMARAVADIVELU. B. A linguística aplicada na era da globalização. In. Por uma linguística aplicada interdisciplinar. São Paulo, Parábola Editorial, 2006.

LINDSTRAND, F. Interview with Gunther Kress. Designs for Learning, Burlington, Volume 1 / Number 2 / Dec, 2008.

MARCELINO, R. Estudos de poder da imprensa. A prática de reportar como componente do dispositivo disciplinar. Dissertação apresentada à Pós-gradução em Comunicação da UFF, 2013.

MOITA LOPES, L. Discourse Analysis and Syllabus Design: An Approach to the Teaching of Reading. Doctoral thesis, Institute of Education, University of London, 1986.

MOTTA, L. E. Sobre “Quem Tem Medo de Alhusser?” de Carlos Henrique Escobar. Achegas.net, Rio de Janeiro, n. 44 jan/Dez 2011.

ORLANDI, E. A sociolinguística, a teoria da enunciação e a análise do discurso.

Sobre o discurso. Série-Estudos, Uberaba, v. 6, 1981. . (org.) Discurso fundador. Campinas; Pontes, 1993. A linguagem e seu funcionamento. São Pulo; Brasiliense 1983.

PINTO, M. J, Comunicação e discurso. Introdução à análise de discursos. São Paulo; Hacker editores, 1999, 2002. $1^{\mathrm{a}}$ e $2^{\mathrm{a}}$ edições. 


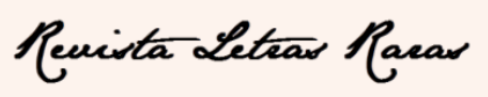

ISSN: $2317-2347$ - v. 8, n. 3 (2019)

- As marcas linguísticas da enunciação. Esboço de uma gramática enunciativa do português. Tese de doutorado apresentada à coordenação dos cursos de pós-graduação da Escola de Comunicação da UFRJ. 1988.

. [1971] A Mensagem Narrativa. In. BARTHES, R. et al. Análise estrutural da narrativa. Petrópolis; Vozes, 2008.

PÊCHEUX, M. [1978] Semântica e Discurso: Uma Crítica a Afirmação do Obvio.

Campinas, Ed. da Unicamp, 1997.

. [1980] Overture du Colloque. In. CONEIN, B et al. Colloque Matérialités Discursives. Lille: Presses Universitaires de Lille, 1981.

PÊCHEUX, M.; FUCHS, C. Mises au point et perspectives à propos de l'analyse automatique du discours. Langages, 37, 1975, p.7-80.

RICOUER, P. [1965] The Conflict of Interpretations. Evanston; Northwestern University Press, 1974.

SPRÍCIGO, S. Uma apresentação da Revista de Cultura Vozes. Boletim de Pesquisa NELIC v. 2, n. 3 - Leituras do periodismo cultural. Florianópolis, 1998.

VAN DIJK, T. News as discourse. London; Routledge, 1988.

Prejudice in Discourse. An analysis of ethnic prejudiced in cognition and conversation. Amsterdam/Philadelphia: John Benjarnins Publishing Company, 1984.

VASCONCELOS, G. [1977] Ideologia Curupira. Análise do discurso Integralista. São Paulo; Editora Brasiliense, 1979.

Trinta anos depois: ideologia curupira. Locus: Revista de História, Juiz de Fora, v. 30, n.1 p. 11-15, 2010. 